\title{
Estimation of Genetic Variability, Heritability and Genetic Advance of Some Wollega Coffee (Coffea arabica L.) Landrace in Western Ethiopia Using Quantitative Traits
}

\author{
Dawit Merga $^{1, *}$, Hussein Mohammed ${ }^{2}$, Ashenafi Ayano1 \\ ${ }^{1}$ Ethiopian Institute of Agricultural Research, Jimma Agricultural Research Center, Jimma, Ethiopia \\ ${ }^{2}$ School of Plant and Horticultural Sciences, Hawassa University College of Agriculture, Hawassa, Ethiopia
}

Email address:

dawitmerga@gmail.com (D. Merga)

${ }^{*}$ Corresponding author

To cite this article:

Dawit Merga, Hussein Mohammed, Ashenafi Ayano. Estimation of Genetic Variability, Heritability and Genetic Advance of Some Wollega Coffee (Coffea arabica L.) Landrace in Western Ethiopia Using Quantitative Traits. Journal of Plant Sciences.

Vol. 9, No. 4, 2021, pp. 182-191. doi: 10.11648/j.jps.20210904.18

Received: July 16, 2021; Accepted: July 28, 2021; Published: August 30, 2021

\begin{abstract}
Arabica coffee is the predominant commodity in contributing for foreign exchange in Ethiopia and improvement for yield and other desirable traits is highly momentous. Estimating genetic diversity is a prerequisite activity in plant breeding program for crop improvement. This study was designed to determine the extent of genetic variability among Wollega coffee landrace and importance of gene revealed in traits. The 26 genotypes were tested during the 2016/2017 cropping season at Mugi and Haru sub- enters using RCBD. The combined analysis manifested significant difference among genotypes only in node number per primary branch (NNPB), fruit traits and Coffee leaf rust (CLR) although significant difference recorded for 18 and 22 of the 23 traits at Haru and at Mugi, respectively. The difference between environments was significant for all traits, except for CLR, yield (YLD), leaf, some fruit and bean traits. Performance at Haru was less than at Mugi for all traits showed significant difference. Genotype x environment (GEI) was significant for all traits excluding NNPB, leaf length (LL), fruit width and CLR indicating inconsistency performance of Coffee genotypes. At Haru, high phenotypic coefficient of variation (PCV $>20 \%)$ recorded for YLD (25.5\%), CLR (110.0\%) and number of secondary branch (NSB) (22.0\%), but High genotypic coefficient of variation (GCV $>20 \%$ ) recorded only for CLR (99.6\%). At Mugi, High PCV and GCV (>20\%) recorded for YLD (38.6\%) and CLR (98.4\%). Heritability ranged from $10.0 \%$ (YLD) to $88.0 \%$ (BW) while genetic advance (GAM) ranged from $1.5 \%$ (LL) to $32.4 \%$ (NSB) at Haru. At Mugi, Heritability ranged between $31 \%$ (CLR) and $84.0 \%$ (bean thickness) and between 3.3\% (LL) and 44.0\% (YLD) for GAM. The present results elucidate the existence of moderate genetic diversity among genotypes for some traits at individual location indicating the possibility of improvement for desired traits via selection. For further diversity analysis, molecular characterization methods need to be carried out.
\end{abstract}

Keywords: Coffea arabica L., Genetic Advance, Genotypic Variance, Heritability, Phenotypic Variance

\section{Introduction}

Coffee belongs to the family Rubiaceae and the genus Coffea $[1,2]$, in which there are at least 141 species [3]. However; the only two of these species commercially used are Arabica coffee (Coffea arabica L.) providing $60 \%$ and Coffee canephora (Coffea canephora Pierre ex A. Froehner) providing $40 \%$ of world's production [4]. C. arabica $\mathrm{L}$. is the only allotetraploid $(2 n=4 x=44)$ and a predominantly selfpollinating species and C. canephora $\mathrm{P}$. is a cross pollinating diploid $(2 n=2 x=22)$ species $[5,6]$.

Even though Arabica coffee grown and produced in different part of the World's countries, genetically diverse species exist in Ethiopia than anywhere else in the world. This enhanced botanists and scientists to agree that Ethiopia is the center of origin, diversification and dissemination of the Coffea arabica L. plant [7]. According to Labouisse and Bayetta [8], Ethiopia is considered as the diversification for Arabica coffee (Coffea arabica L) and high genetic variability exist for yield and yield components, diseases and pest 
resistance traits. Similarly, as study carried out by Mesfin and Bayetta [9] on Arabica coffee collection from Hararge and Abdulfeta [10] from Tepi, and another study by Olika et al. [11] on Limmu Coffea arabica L. collection using quantitative traits indicated the existence of high genetic diversity.

Although coffee is growing in different Ethiopian geography, it is produced in immense within specific agroecological zones and political boundaries in Ethiopia. Thus, North Zone (Amhara and Benishangul Gumuz), South West Zone (Wollega, Illubabor, Jimma-Limu, Kafa, Tepi and Bench Maji), Rift Zone (Rift North and Rift South), South East Zone (Sidamo, Yergacheffe, Bale and Central Eastern Highland) and Harar Zone (Arsi, East Harage and West Harage) are the five main coffee growing Zone areas in Ethiopia [12]. From these Zones, the main coffee producing areas of Ethiopia are found within the South West and South East. The presence of high environmental diversity, distinct variation in coffee quality within and between regions [13] and location specificity of improved varieties [14] forced breeder to evaluate the genetic divergence for each location by collecting from that area. This is crucial to release coffee variety of high yielder and maintaining typical quality for that area.

Despite Wollega is one of the potential Arabica coffee growing areas of Western Ethiopia, only four Arabica coffee varieties had been released from this areas' coffee gene pool (Haru-I, Cala, Menesibu and Sinde) by pure line variety development. The released varieties give lower yield as compared to varieties released from coffee landrace of south western Ethiopia. The major contributing factors for such low yield in Wollega include limited exploitation of the existing germplasm of the areas and lack of well characterized and distinctly variable breeding material that is readily available for breeding work [1]. This implies that knowledge of genetic diversity among elite breeding materials and understanding the significance of gene in traits is important for yield improvement of the crop. Hence, the present study was carried out with the intention to estimate the extent of genetic variability, broad sense heritability and expected genetic advance of some Wollega Arabica coffee landrace based on yield and yield related traits for the next breeding program.

\section{Materials and Methods}

Description of Studying Areas

The experiment was conducted at Haru and Mugi agricultural research sub centers which are sub centers of Jimma agricultural research center. Mugi found in kellem Wollega zone at $34^{\circ} 00^{\prime}$ to East and $8^{\circ} 40^{\prime}$ to North. It is 610 $\mathrm{km}$ far from Jimma city to North West direction. It is located at altitude of $1570 \mathrm{~m}$ a.s.l and receive $1655 \mathrm{~mm}$ annual rain fall. Also, it has Nitosol soil type [15] and minimum $17^{\circ} \mathrm{C}$ and maximum $29^{\circ} \mathrm{C}$ temperature for this location. Haru is located $35^{\circ} 47^{\prime} 56^{\prime \prime}$ to East and $8^{\circ} 59^{\prime} 21^{\prime \prime}$ to North, in West Wollega zone at altitude of $1752 \mathrm{~m}$ a.s.1. and $360 \mathrm{~km}$ away from Jimma city. The area receives annual rain fall of 1727 $\mathrm{mm}$ which is unimodal, the peak being July. In addition, it has an average maximum and minimum temperature of $27^{\circ} \mathrm{C}$ and $16^{\circ} \mathrm{C}$ respectively [16] and sand clay loam soil.

Experimental Materials, Design and Agronomic practice

The experiment was conducted during 2017/2018 cropping season, on 22 promising Wollega coffee accessions which were taken from different batch of base collections with four standards check (Table 1). RCBD design in three replications was used. The study was superimposed on the already established coffee planted in July 2015 with six plants per plot using spacing of $2 \mathrm{~m}$ by $2 \mathrm{~m}$ and $4 \mathrm{~m}$ between replications. All field management applied as recommended [17].

Table 1. Description of Wollega coffee Accessions background.

\begin{tabular}{|c|c|c|c|c|}
\hline No. & Accessions & Woreda & Peasants Association & Collection altitude (m. a.s.l) \\
\hline 1 & W02/98 & Haru & Wora Baro & 1740 \\
\hline 2 & W34/98 & Haru & Wora Baro & 1790 \\
\hline 3 & W98/98 & Haru & Chageli & 1800 \\
\hline 4 & W141/98 & Gimbi & H. Giorgis & 1620 \\
\hline 5 & W163/98 & Gimbi & Homa Arsama & $1600-1670$ \\
\hline 6 & W167/98 & Gimbi & Homa Arsama & $1600-1670$ \\
\hline 7 & W175/98 & Gimbi & Homa Arsama & $1600-1670$ \\
\hline 8 & W188/98 & Gimbi & Homa Biribir & $1550-1600$ \\
\hline 9 & W191/98 & Gimbi & Homa Biribir & $1500-1570$ \\
\hline 10 & W203/98 & Gimbi & Siba Yesus & 1560 \\
\hline 11 & W212/98 & Gimbi & Sibo Charo & 1560 \\
\hline 12 & W01/99 & Haru & Guracha Holata & 1660 \\
\hline 13 & W40/99 & Haru & Dogi Adere & 1720 \\
\hline 14 & W109/99 & Ayira Gliso & - & 1600 \\
\hline 16 & W09/00 & Ayira Guliso & Boke Keda & 1600 \\
\hline 17 & W50/00 & Ayira Guliso & Kurfessa birbir & 1580 \\
\hline 18 & W52/00 & Ayira Guliso & Kurfessa birbir & 1520 \\
\hline 19 & W06/01 & Ayira Guliso & Lalo Asella & 1600 \\
\hline 20 & W08/01 & Ayira Guliso & Tosiyo mole & 1620 \\
\hline 21 & W15/01 & Ayira Guliso & Buro Hasabar & 1700 \\
\hline 22 & W38/01 & Ayira Guliso & Nebo Daleti & 1600 \\
\hline
\end{tabular}




\begin{tabular}{lllll}
\hline \multicolumn{2}{ll}{ Checks $/$ Released varieties } & & \\
\hline 1 & Mana sibu (W78/98) & Haru & Haru & \\
2 & Sinde (W92/98) & Haru & Haru & 1550 \\
3 & Chala (W76/98) & Haru & Haru & 1590 \\
4 & Haru-I (66/98) & Haru & Haru & 1740 \\
\hline
\end{tabular}

\section{Methods and Data Recorded}

Three randomly selected plants from each plot were used to record the plant growth parameters. However; for yield and disease data all plants per plot were used to record the necessary data. Data were recorded following the IPGRI descriptor [18]. Data taken during the study were Plan height $(\mathrm{PH})(\mathrm{cm})$, Height up to first primary branch (HFPB) $(\mathrm{cm})$, Total node number of main stem (TNN), Internodes length of the main stem (IL) $(\mathrm{cm})$, Diameter of the main stem (DM) $(\mathrm{mm})$, Stem habit (SH), Number of primary branches (NPB), Number of secondary branches (NSB), Average length of primary branches (ALPB) (cm), Number of nodes per primary branch (NNPB), Number of bearing primary branches (NBPB), Percentage of bearing primary branches (PBPB) (\%), Leaf length (LL) (cm), Leaf width (LW) (cm), Leaf area (LA) $\left(\mathrm{cm}^{2}\right)$, Canopy diameter $(\mathrm{CD})(\mathrm{cm})$, Bean length $(\mathrm{BL})(\mathrm{mm})$, Bean width $(\mathrm{BW})(\mathrm{mm})$, Bean thickness $(\mathrm{BT})(\mathrm{mm})$, Fruit length $(\mathrm{FL})(\mathrm{mm})$, Fruit width $(\mathrm{FW})(\mathrm{mm})$ Fruit thickness (FT) (mm), Clean bean yield (YLD) (Kg/ha) and Coffee Leaf Rust (CLR).

Analyses of Variance

Analysis of variance (ANOVA) of RCBD was used to see variability using proc mixed procedure of SAS version 9.0 software package [19] (Table 2). Random model which included genotype and location as random factor and genotype $\times$ location interaction was used following statistical model: $\mathrm{Y}_{\mathrm{ijk}}=\mu+\mathrm{G}_{\mathrm{i}}+\mathrm{L}_{\mathrm{j}}+\mathrm{B}_{\mathrm{k}}\left(\mathrm{L}_{\mathrm{j}}\right)+\mathrm{GL}_{\mathrm{ij}}+\varepsilon_{\mathrm{ijk}}$. Where, $\mathrm{Y}_{\mathrm{ijk}}$ was the observation for genotype ' $i$ ' at location ' $j$ ' in replication ' $k$ '. In the model ' $\mu$ ' was the overall mean ' $\mathrm{G}_{\mathrm{i}}$ ' the effect of the genotype ' $\mathrm{i}$ ', ' $\mathrm{L}_{\mathrm{j}}$ ' was the effect of environment ' $\mathrm{j}$ ', ' $\mathrm{B}_{\mathrm{k}}$ ' block effect, ' $\mathrm{GL}_{\mathrm{ij}}$ ' the interaction between genotype and location or environment and ' $\varepsilon_{\mathrm{ijk}}$ ' was the random error associated with the' $k^{\text {th }}$ observation on genotype ' $i$ ' in environment. For combined analysis of variance over locations, the homogeneity of error variance was tested using F-max method of Hartley [20]. Traits that showed heterogeneous error variances were square root transformed before combining.

Table 2. ANOVA table skeleton for combined analysis.

\begin{tabular}{llll}
\hline SV & DF & MS & EMS \\
\hline R (location) & $1(\mathrm{r}-1)$ & MSr & $\sigma^{2} \mathrm{e}+\mathrm{gl} \sigma^{2} \mathrm{r}$ \\
Location & $1-1$ & MSl & $\sigma^{2} \mathrm{e}+\mathrm{r} \sigma^{2} \mathrm{gl}+\mathrm{gr} \sigma^{2} 1$ \\
Genotype & $\mathrm{g}-1$ & $\mathrm{MSg}$ & $\sigma^{2} \mathrm{e}+\mathrm{r} \sigma^{2} \mathrm{gl}+\mathrm{rl} \sigma^{2} \mathrm{~g}$ \\
GxE & $(\mathrm{g}-1)(1-1)$ & MSgxl & $\sigma^{2} \mathrm{e}+\mathrm{r} \sigma^{2} \mathrm{gl}$ \\
Error & $(\mathrm{r}-1)(\mathrm{g}-1) 1$ & MSerror & $\sigma^{2} \mathrm{e}$ \\
\hline
\end{tabular}

SV-Source of variance, DF- Degree of freedom, MSMean square, EMS-Expected mean square GXL-Genotype by Location interaction, 1-location, r-replication and ggenotype, Genotypic and Phenotypic variance:- estimated as Johnson et al. [21]:

$\sigma^{2} \mathrm{~g}=\frac{M S g-M S e}{r}$ for individual location, $\sigma^{2} \mathrm{p}=\sigma^{2} \mathrm{~g}+\sigma^{2} \mathrm{e} / \mathrm{r}$ (Mse/r) $\sigma^{2} \mathrm{~g}=\frac{M S g-M S g l}{r l}$ for over location, $\sigma^{2} \mathrm{gl}=\frac{M S g l-M S e}{r}$, $\sigma^{2} \mathrm{p}=\sigma^{2} \mathrm{~g}+\frac{\sigma^{2} e}{r l}+\frac{\sigma^{2} g l}{l}$. Where, $\sigma^{2} \mathrm{p}=$ phenotypic variance, $\sigma^{2}$ $\mathrm{g}=$ genotypic variance, $\sigma^{2} \mathrm{gl}=$ variance of genotype $\mathrm{x}$ environmental interaction, $\sigma^{2} \mathrm{e}=$ environmental variance (Error mean square), MSg = mean square of genotypes, MSe $=$ mean square of error and $\mathrm{r}=$ Number of replications

Phenotypic coefficient of variation $(\mathrm{PCV})=\frac{\sqrt{\sigma^{2} p}}{\bar{x}} * 100$, Genotypic coefficient of variation $(\mathrm{GCV})=\frac{\sqrt{\sigma^{2} g}}{\bar{x}} * 100$ and Environmental coefficient of variation $(\mathrm{ECV})=\frac{\sqrt{\sigma^{2} e}}{\bar{x}} * 100$, Where $\bar{x}=$ sample mean

PCV and GCV categorized as low (0-10\%), moderate (10$20 \%)$ and high $(>20)[22]$.

Estimation of heritability in broad sense:- computed as Allard [23] and, Holland et al.[24].
$H b^{2}=\frac{\sigma_{g}^{2}}{\sigma_{P}^{2}}$ For individual location, $H b^{2}=\frac{\sigma_{g}^{2}}{\sigma_{p}^{2}}$ Where $\sigma^{2} \mathrm{p}=$ $\sigma^{2} \mathrm{~g}+\frac{\sigma^{2} e}{r l}+\frac{\sigma^{2} g l}{l}$ for over location. Heritability classified i low (0-20\%), moderate (20-50\%) and high (>50\%) [25].

Estimation of expected genetic advance:- calculated as suggested by Allard [23] as: $\mathrm{GA}=(\mathrm{K})(\sigma \mathrm{p})\left(\mathrm{Hb}^{2}\right)$ Where, GA $=$ expected genetic advance, $\sigma \mathrm{p}=$ the phenotypic standard deviation, $\mathrm{Hb}^{2}=$ heritability in broad sense, $\mathrm{K}=$ Selection differential ( $\mathrm{K}=2.06$ at $5 \%$ selection intensity).

Genetic advance as percent of Mean - GAM $=(\mathrm{GA} / \mathrm{X})$ * 100. Where GA and $X$ represent genetic advance and sample mean. It categorized low (0-10\%), moderate (10-20\%) and high $(>20 \%)[21]$.

\section{Results and Discussions}

Analysis of Variance

The results of most traits from analysis of variance of the two individual location indicated that the existence of significance difference between genotypes at probability level of $(\mathrm{p}<0.05)$ and $(\mathrm{p}<0.01)$ (Table 3). At Mugi, morphological traits like Plant height $(\mathrm{PH})$, total node number of main stem (TNN), inter node length of main stem (IL), number of primary branch (NPB), number of bearing 
primary branch (NBPB), percentage of bearing primary branch (PBPB), fruit thickness (FT) and bean characters revealed highly significantly different between genotypes $(p<0.01)$ (Table 3). Whereas like height up to the first primary branch (HFPB), diameter of primary branch (DM), canopy diameter (CD), number of secondary branch (NSB), average length of primary branch (ALPB), number of node per primary branch (NNPB), leaf and fruit characters and yield showed significantly difference among genotypes $(\mathrm{P}<0.05)$ at Mugi.

At Haru, traits like PH, HFPB, TNN, DM, CD, NPB, NSB, NBPB, ALPB, NNPB, leaf width (LW), fruit and beans characters revealed highly significantly different among genotypes $(\mathrm{P}<0.01)$ (Table 3). However, IL, PBPB, leaf length (LL), leaf width (LW) and yield (YLD) showed nonsignificantly different at Haru. Coffee genotypes did not differ significantly in coffee rust disease infection tolerance at Mugi, but significantly different at Haru. There was significant difference among 26 coffee genotypes at both locations in PH, HFPB, TNN, DM, CD, NPB, NSB, ALPB, NNPB, LW and in fruit (fruit length (FL), fruit width (FW), fruit length (FT)) and in bean (bean length (BL), bean width (BW), bean thickness (BT)) traits indicating the existence of genetic variability among the coffee genotypes included in this study.

Table 3. Analysis of variance of quantitative traits.

\begin{tabular}{|c|c|c|c|c|c|c|c|c|}
\hline & & Mugi & & & Haru & & & \multirow{3}{*}{ CV (\%) } \\
\hline Plant & Blocks & Genotypes & Error & \multirow{2}{*}{ CV (\%) } & Blocks & Genotypes & Error & \\
\hline Traits & $(d f=2)$ & $(d f=25)$ & $(d f=50)$ & & $(d f=2)$ & $(d f=25)$ & $(d f=50)$ & \\
\hline $\mathrm{PH}$ & $2382.27^{*}$ & $1226.31 * *$ & 513.87 & 11.09 & $3131.11 * *$ & $546.53 * *$ & 139.65 & 7.76 \\
\hline HFPB & $0.65 \mathrm{~ns}$ & $30.72 *$ & 14.19 & 13.47 & $3.25 \mathrm{~ns}$ & $39.50 * *$ & 5.12 & 9.57 \\
\hline TNN & $8.33 \mathrm{~ns}$ & $19.92 * *$ & 8.51 & 10.2 & $39.27 * *$ & $10.67 * *$ & 1.67 & 5.68 \\
\hline $\mathrm{DM}$ & $36.07 \mathrm{~ns}$ & $49.62 *$ & 26.05 & 12.57 & $59.10 * *$ & $22.85 * *$ & 7.03 & 8.27 \\
\hline IL & $1.42 *$ & $1.29 * *$ & 0.43 & 10.2 & $0.73 \mathrm{~ns}$ & $0.40 \mathrm{~ns}$ & 0.25 & 8.4 \\
\hline NPB & $11.81 \mathrm{~ns}$ & $49.33 * *$ & 21.65 & 11.81 & $95.55 * *$ & $39.74 * *$ & 8.68 & 9.16 \\
\hline NSB & $9.74 \mathrm{~ns}$ & $180.18^{*}$ & 99.88 & 20.36 & $78.65 \mathrm{~ns}$ & $177.79 * *$ & 50.77 & 20.38 \\
\hline NBPB & $18.81 \mathrm{~ns}$ & $16.41 * *$ & 6.98 & 12.84 & $71.12 * *$ & $13.39 * *$ & 4.88 & 16.13 \\
\hline PBPB & $222.29 *$ & $129.11 * *$ & 58.34 & 14.47 & $162.68 * *$ & $47.51 \mathrm{~ns}$ & 29.2 & 12.72 \\
\hline ALPB & $264.49 *$ & $125.08^{*}$ & 70.38 & 9.43 & $131.68 * *$ & $73.95 * *$ & 18.9 & 5.27 \\
\hline NNPB & $7.69 \mathrm{~ns}$ & $6.32 *$ & 3.45 & 9.54 & $1.23 \mathrm{~ns}$ & $4.22 * *$ & 1.51 & 5.55 \\
\hline LL & $3.64 * *$ & $0.82 *$ & 0.44 & 4.34 & $0.58 \mathrm{~ns}$ & $0.61 \mathrm{~ns}$ & 0.46 & 4.31 \\
\hline FL & $1.60 *$ & $1.35^{*}$ & 0.63 & 5.79 & $1.54 *$ & $1.43 * *$ & 0.4 & 4.62 \\
\hline FW & $0.14 \mathrm{~ns}$ & $0.36^{*}$ & 0.18 & 3.89 & $0.54 \mathrm{~ns}$ & $0.63 * *$ & 0.17 & 4.21 \\
\hline FT & $0.10 \mathrm{~ns}$ & $0.29 * *$ & 0.13 & 3.85 & $0.63 *$ & $0.87 * *$ & 0.13 & 3.95 \\
\hline BL & $2.32 * *$ & $0.47 * *$ & 0.05 & 3.03 & $1.10 * *$ & $0.32 * *$ & 0.06 & 3.11 \\
\hline BW & $0.45^{* *}$ & $0.07 * *$ & 0.03 & 3.59 & $0.24 * *$ & $0.16^{* *}$ & 0.02 & 2.91 \\
\hline BT & $0.04 \mathrm{~ns}$ & $0.12 * *$ & 0.02 & 6.34 & $0.01 \mathrm{~ns}$ & $0.05 * *$ & 0.01 & 5.1 \\
\hline YLD & $121330.89 \mathrm{~ns}$ & $105462.36 * *$ & 47060.28 & 44.63 & $137784.69 * *$ & $23374.85 \mathrm{~ns}$ & 21118.03 & 42.01 \\
\hline CLR1 & $37.66 \mathrm{~ns}$ & $156.88 \mathrm{~ns}$ & 104.65 & 62.19 & $145 \mathrm{~ns}$ & $218.40 * *$ & 30.63 & 38.63 \\
\hline CLR & (121.91ns) & (212.66ns) & $(146.80)$ & (98.61) & (113.61ns) & $(252.86 * *)$ & $(45.45)$ & $(80.79)$ \\
\hline
\end{tabular}

$*, * *, * * * \&$ ns- represent significant at probability level of $0.05,0.01,0.001$ and non-significant respectively. CLR1- Arcsine transformed coffee leaf rust data

\section{Combined Analysis of Variance}

All traits showed homogenous variance except $\mathrm{PH}, \mathrm{TNN}$, ALPB and CLR. Traits showed non-homogenous variance transformed by square transformation method before combined analysis (Table 4). Combined analysis of variance revealed highly significant $(\mathrm{p}<0.001)$ for HFPB, TNN, NSB and FW (Table 4) among locations. Traits like PH, DM, CD, NPB, PBPB, IL, NNPB and BT showed highly significant difference (0.01) among locations and trait like ALPB showed significant difference (0.05). In all these traits, means were higher at Mugi than at Haru (Table 5). This is due to the ecological nature of Mugi which is known for its high humidity in most seasons and high temperature relative to Haru location which experienced peak humidity in summer season. Mota et al. [26] suggested that lower temperature would trigger declining growth rate of Coffea arabica L. Location effect on CLR, yield, leaf, fruit and bean traits was non-significant except for FW and BT. In line with the present results, Abdulfeta [10] and Masreshaw [27] reported that the existence of variability among Arabica coffee germplasm which were collected from south western Ethiopia using agronomic traits used in this study.

Our results also demonstrated that Haru and Mugi did little differ in bean yield (346 and $486 \mathrm{~kg} \mathrm{ha}^{-1}$ at Haru and Mugi respectively) although non-significant. The highest reductions in means at Haru recorded for plant height $(25.5 \%)$, total number of nodes on the main stem (TNN) (20.6\%), number of secondary branches $(28.8 \%)$ and NBPB (33.4\%). Reductions of 10 to $20 \%$ at Haru as compared to that at Mugi were observed in HFPB (15.5\%), CD (13.1\%), NPB (18.4\%), PBPB (19.5\%), and FW (10.1\%). As shown in Table 5, for the remaining traits (IL, ALPB, NNPPB and BT) reductions in means at Haru were less than $10 \%$.

The difference between the genotypes was significant for 
only NNPB, FL, FW, FT, and CLR although the difference between genotypes was significant for 18 and 22 of the 23 traits at Haru and at Mugi, respectively. In the combined analysis these differences were masked by the highly significant GxE interaction against which genotype mean squares were tested. GxE interaction was significant for all traits except for NNPB, LL, FW and CLR. These interactions, against which genotypic effects were tested were large in most of the traits and contributed more than $25 \%$ to total treatment sum of square (SS) $(\mathrm{G}+\mathrm{E}+\mathrm{GEI})$ in 16 of the 23 traits (Table 4). The Genotype contributed more than $25 \%$ to 18 of the 23 traits. The genotype played minor role (contributed less than 20\%) in determining traits such as PH (11.7\%), TNN (13.6\%), DM (13.0\%) and NBPB (17.1\%). These traits were determined mainly by the environment $(70.5 \%, 64.0 \%, 61.2 \%$, and $71.2 \%$, respectively). The genotype played the major role in the determination of traits such as FL (70.1\%), FT (69.0\%) and CLR (83.2\%).

The highly significant GxE interaction showed the noncorrespondence between the performances of genotypes at the two locations, i.e., inconsistency of performance of genotypes over the two locations. For IL (45.6\%), LW $(48.5 \%)$ and leaf area (LA) (43.8\%) GxE made large contribution to treatment SS (Table 4). Under such circumstances selection by mean over locations does not identify genotypes that manifest high performance at both locations. Thus, it seems better to divide coffee growing areas into similar ecologies, some similar to Haru and others similar to Mugi and focus on developing coffee varieties with specific adaptation to these ecologies. In line with this, Fikadu et al. (2016) [28] reported that similar result of Gx E interaction using 14 characters used in the present study. For FW where GxE contributed only $8.6 \%$ to treatment SS and the genotype was the major determinant of the trait $(65.9 \%)$. The result also indicated that for NNPB, LL and CLR where GxE contributed less to treatment SS and genotype contribution was the dominant $(51.8 \%, 51.1 \%$ and $83.2 \%$ respectively), selecting elite genotypes based on mean over the two locations may identify common genotypes that are superior at both locations.

Table 4. Over location combined analysis of variance for quantitative traits.

\begin{tabular}{|c|c|c|c|c|c|c|c|c|c|}
\hline \multirow{2}{*}{ Traits } & MSB & MSG & Gcont. & MSL & Econt. & MSG* & L GxEcont. & MSE & \\
\hline & $(\mathrm{df}=4)$ & $(\mathrm{df}=25)$ & $(\%)$ & $(d f=1)$ & $(\%)$ & $(\mathrm{df}=25)$ & $(\%)$ & $(d f=100)$ & CV (\%) \\
\hline \multirow[t]{2}{*}{$\mathrm{PH}$} & $4.15 * *$ & $0.95 \mathrm{~ns}$ & & $147.36^{* *}$ & & $1.48 * * *$ & & 0.46 & 5.12 \\
\hline & $\left(4887.75^{* *}\right)$ & (700.46ns) & 11.7 & $\left(105798.44^{* *}\right)$ & 70.5 & $(1072.39 * * *)$ & 17.9 & $(326.76)$ & $(10.23)$ \\
\hline HFPB & $2.11 \mathrm{~ns}$ & $39.95 \mathrm{~ns}$ & 40.2 & $730.64 * * *$ & 29.4 & $30.26 * * *$ & 30.4 & 9.5 & 11.95 \\
\hline \multirow[t]{2}{*}{$\mathrm{TNN}$} & $0.26 * *$ & $0.11 \mathrm{~ns}$ & & $13.19^{* * *}$ & & $0.18 * * *$ & & 0.05 & 4.38 \\
\hline & $\left(35.84^{* *}\right)$ & (11.55ns) & 13.6 & $(1357.89 * * *)$ & 64 & $(19.04 * * *)$ & 22.4 & $(5.22)$ & $(8.91)$ \\
\hline \multirow[t]{2}{*}{ DM } & $0.35 *$ & $0.16 \mathrm{~ns}$ & & $19.25 * *$ & & $0.33 * * *$ & & 0.11 & 5.61 \\
\hline & $(47.59 *)$ & (24.21ns) & 13 & $\left(2853.14^{* *}\right)$ & 61.2 & $(48.25 * * *)$ & 25.9 & $(18.05)$ & (11.69) \\
\hline IL & $2.03 *$ & $0.75 \mathrm{~ns}$ & 36.8 & $9.04 * *$ & 17.6 & $0.93 * * *$ & 45.6 & 0.33 & 9.36 \\
\hline $\mathrm{CD}$ & $798.47 * *$ & $460.09 \mathrm{~ns}$ & 25 & $22637.13 * *$ & 49 & $473.22 * *$ & 25.7 & 224.84 & 17.17 \\
\hline NPB & $64.66 * *$ & 49.39ns & 28.9 & $2045.8^{* *}$ & 47.9 & $39.68 * * *$ & 23.2 & 15.7 & 11.08 \\
\hline NSB & $41.41 \mathrm{~ns}$ & $187.28 \mathrm{~ns}$ & 28 & $7770.10 * * *$ & 46.5 & $170.68 * *$ & 25.5 & 74.77 & 20.58 \\
\hline NBPB & $9.00 \mathrm{~ns}$ & $17.68 \mathrm{~ns}$ & 17.1 & $1841.92 * *$ & 71.2 & $12.12 * *$ & 11.7 & 7.4 & 15.88 \\
\hline РВPB & $4.05 \mathrm{~ns}$ & $75.90 \mathrm{~ns}$ & 22.2 & $4150.60 * *$ & 48.5 & $100.71 * *$ & 29.4 & 50.39 & 14.9 \\
\hline \multirow[t]{2}{*}{ ALPB } & $0.59 * *$ & $0.30 \mathrm{~ns}$ & & $4.59^{*}$ & & $0.26^{* *}$ & & 0.13 & 3.92 \\
\hline & $(198.08 * *)$ & (105.23ns) & 39.8 & $(1640.02 *)$ & 24.8 & $(93.80 * *)$ & 35.4 & $(44.63)$ & $(7.8)$ \\
\hline NNPB & $4.46 \mathrm{~ns}$ & $7.21 *$ & 51.8 & $84.10^{* *}$ & 24.2 & $3.33 \mathrm{~ns}$ & 23.9 & 2.33 & 7.96 \\
\hline LL & $2.81 * *$ & $0.91 \mathrm{~ns}$ & 51.1 & $8.76 \mathrm{~ns}$ & 19.7 & $0.52 \mathrm{~ns}$ & 29.2 & 0.44 & 4.41 \\
\hline LW & $0.27 *$ & $0.24 \mathrm{~ns}$ & 51.2 & $0.03 \mathrm{~ns}$ & 0.3 & $0.22 * *$ & 48.5 & 0.11 & 5.24 \\
\hline LA & $112 * *$ & $53.93 \mathrm{~ns}$ & 51.6 & $120.58 \mathrm{~ns}$ & 4.6 & $45.83^{*}$ & 43.8 & 27.94 & 8.02 \\
\hline FL & $1.57 *$ & $1.95 *$ & 70.1 & $0.07 \mathrm{~ns}$ & 0.1 & $0.83 *$ & 29.8 & 0.56 & 5.5 \\
\hline FW & $0.34 \mathrm{~ns}$ & $0.74 * *$ & 25.6 & $47.83 * * *$ & 65.9 & $0.25 \mathrm{~ns}$ & 8.6 & 0.19 & 4.13 \\
\hline FT & $0.36^{*}$ & $0.83^{*}$ & 69 & $1.13 \mathrm{~ns}$ & 3.8 & $0.33 * * *$ & 27.2 & 0.14 & 4.02 \\
\hline BL & $1.71 * * *$ & $0.46 \mathrm{~ns}$ & 51.8 & $2.57 \mathrm{~ns}$ & 11.6 & $0.33 * * *$ & 36.6 & 0.05 & 3.11 \\
\hline BW & $0.34 * * *$ & $0.14 \mathrm{~ns}$ & 61.5 & $0.06 \mathrm{~ns}$ & 1.1 & $0.08 * * *$ & 37.4 & 0.02 & 3.26 \\
\hline BT & $0.02 \mathrm{~ns}$ & $0.10 \mathrm{~ns}$ & 43 & $1.67 * *$ & 27.9 & $0.07 * * *$ & 29.1 & 0.02 & 5.79 \\
\hline YLD & $129557.52 * *$ & $69243.67 \mathrm{~ns}$ & 43.2 & $766228.09 \mathrm{~ns}$ & 19.2 & $59593.41 *$ & 37.4 & 34089.15 & 44.38 \\
\hline \multirow[t]{2}{*}{ CLR } & $2.33 \mathrm{~ns}$ & $7.66^{* * *}$ & & $0.08 \mathrm{~ns}$ & & $1.83 \mathrm{~ns}$ & & 1.67 & 53.66 \\
\hline & (117.75ns) & $(387.34 * * *)$ & 83.2 & (1.73ns) & 0 & (78.17ns) & 16.8 & $(96.13)$ & (116.03) \\
\hline
\end{tabular}

*, **, ***and ns- represent significant different at probability level of $0.05,0.01,0.001$ and non-significant different respectively. Gcont.- Genotype contribution, Econt. - Environmental contribution and GXEcont.- Genotypes by environmental contribution. PH-Plant height (cm), HFPB-Height up to the first primary branch (cm), TNN-Total node number of main stem, DM-Diameter of main stem (mm), IL-Internodes' length of main stem (cm), CD-Canopy diameter $(\mathrm{cm})$, NPB-Number of primary branch, NSB-Number of Secondary branch, NBPB-Number of bearing primary branch, PBPB-Percent of bearing primary branch, ALPB-Average length of primary branch $(\mathrm{cm})$, NNPB-Number of nodes per primary branch, LL-Leaf length (cm), LW-Leaf width (cm), LALeaf area $\left(\mathrm{cm}^{2}\right)$, FL-Fruit length $(\mathrm{mm})$, FW-fruit width $(\mathrm{mm})$, FT-Fruit thickness $(\mathrm{mm})$, BL-Bean length (mm), BW-Bean width (mm), BT-Bean thickness (mm), YLD-Yield (kg/ha, CLR-Coffee leaf rust (\%). 
Table 5. Mean separation of quantitative traits among Haru and Mugi locations.

\begin{tabular}{|c|c|c|c|c|c|c|c|c|c|c|c|c|}
\hline \multicolumn{13}{|l|}{ Plant traits } \\
\hline Locations & PH & HFPB & TNN & DM & IL & CD & NPB & NSB & NBPB & PBPB & ALPB & NNPPB \\
\hline Mugi & $204.34 \mathrm{a}$ & $27.97 \mathrm{a}$ & $28.61 \mathrm{a}$ & $40.62 a$ & $6.41 \mathrm{a}$ & $183.47 \mathrm{a}$ & $39.39 a$ & $48.07 \mathrm{a}$ & $20.57 \mathrm{a}$ & $52.79 a$ & $88.94 a$ & $19.49 a$ \\
\hline Haru & $152.26 \mathrm{~b}$ & $23.64 b$ & $22.71 b$ & $32.06 \mathrm{~b}$ & $5.92 b$ & $158.81 \mathrm{~b}$ & $31.83 b$ & $32.20 \mathrm{~b}$ & $13.69 b$ & $42.60 \mathrm{~b}$ & $82.46 \mathrm{~b}$ & $18.02 b$ \\
\hline $\mathrm{RD}$ at Haru $(\%)$ & 25.45 & 15.48 & 20.62 & 21.06 & 7.49 & 13.13 & 18.39 & 28.76 & 33.41 & 19.54 & 7.29 & 7.54 \\
\hline LSD & 7.67 & 1.30 & 0.96 & 1.79 & 0.24 & 6.30 & 1.66 & 3.63 & 1.14 & 2.98 & 2.98 & 0.64 \\
\hline
\end{tabular}

Table 5. Continued.

\begin{tabular}{|c|c|c|c|c|c|c|c|c|c|c|c|}
\hline Locations & $\mathbf{L L}$ & LW & LA & FL & FW & FT & BL & BW & BT & YLD & CLR \\
\hline Mugi & $15.24 \mathrm{a}$ & $6.36 \mathrm{a}$ & $64.99 \mathrm{a}$ & $13.67 \mathrm{a}$ & $11.00 \mathrm{a}$ & $9.25 \mathrm{a}$ & $7.37 \mathrm{a}$ & $4.71 \mathrm{a}$ & $2.23 a$ & $486.08 \mathrm{a}$ & $8.55 a$ \\
\hline Haru & $15.71 \mathrm{a}$ & $6.33 a$ & $66.75 \mathrm{a}$ & $13.62 \mathrm{a}$ & $9.90 \mathrm{~b}$ & $9.11 \mathrm{a}$ & $7.33 \mathrm{a}$ & $4.76 \mathrm{a}$ & $2.03 \mathrm{~b}$ & $345.91 \mathrm{a}$ & $8.34 \mathrm{a}$ \\
\hline RD at Haru $(\%)$ & -3.11 & 0.46 & -2.71 & 0.31 & 10.06 & 1.85 & -3.49 & -0.85 & 9.31 & 28.83 & 2.47 \\
\hline LSD & 0.58 & 0.13 & 2.22 & 0.24 & 0.14 & 0.16 & 0.14 & 0.06 & 0.04 & 171.32 & 4.13 \\
\hline
\end{tabular}

Note-traits assigned by same letter were not significantly different. RD-Reduction, LSD-least significance difference, PH-plant height, HFPB -height up to the first primary branch, TNN-total number of nodes of main stem, DM-main stem diameter, IL-inter node length of main stem, CD-canopy diameter, NPBnumber of primary branch, NSB-number of secondary branch, NBPB-number of bearing primary branch, PBPB-percentage of bearing primary branch, ALPBaverage length of primary branch, NNPB- number of nodes per primary branch, LL-leaf length, LW-leaf width, LA-leaf area, FL-fruit length, FW-fruit width, FT- fruit thickness, BL-bean length, BW-bean width, BT-bean thickness, YLD-yield and CLR-Coffee leaf rust.

Genotypic and Phenotypic variance at Haru and at Mugi

Results of variability study for 23 traits of coffee at Haru and Mugi were presented in Tables 6 and 7 respectively. At Haru, high phenotypic coefficient of variation (PCV) $(>20 \%)$ was observed for YLD (25.5\%), CLR (110.0\%) and NSB (22.0\%). These traits had a very wide range; from 172 to $507 \mathrm{~kg} \mathrm{ha}^{-1}$ for YLD (a range of $97 \%$ of the mean), from 0.4 to $42 \%$ infection by CLR (a range of $496 \%$ of the mean) and from 26 to 58 secondary branches per tree (a range of $91 \%$ of the mean). Moderate PCV (10-20\%) was observed for NBPB (15.4\%), HFPB (15.4\%), and NPB (11.3\%); these traits had intermediate range as percent of the mean $(60,63$ and $45 \%$, respectively). Our results revealed that for all other 17 traits phenotypic coefficient of variability was low $(<10 \%)$.

High genotypic coefficient of variation (GCV) $(>20 \%)$ was observed for only CLR (99.6\%). Moderate GCV (10$20 \%$ ) was observed for NBPB (12.3\%), HFPB (14.3\%), NPB $(10.0 \%)$ and for NSB (18.6\%). For the remaining 18 traits GCV was low $(<10 \%)$ indicating that the genotypic variability between the Wollega coffee accessions studied was narrow for most of the traits. This may be due to the fact that these 22 accessions were elite selections from many base collections included in the preliminary screening studies. The present result confirmed with Getachew et al. [34] who reported that low GCV and high PCV for yield traits and low for bean traits.

At Mugi, high PCV (>20\%) was observed for bean yield (38.6\%) and for CLR (98.4\%) likewise at Haru. These two traits had wide range; 257 to $1236 \mathrm{~kg} \mathrm{ha}^{-1}$ for bean yield with range of $201.4 \%$ of the mean and 1.0 to $37.8 \%$ infection by coffee leaf rust with range of $430 \%$ of the mean. Moderate PCV (10-20\%) was recorded for NBPB, PBPB, PH, HFPB, DM, IL, NPB and NSB whose PCV varied between 10.0\% for $\mathrm{PH}$ to $15.8 \%$ for NSB and whose range as percent of the mean varied from $35.2 \%$ for $\mathrm{PH}$ to $75.8 \%$ for NSB. For the remaining 13 traits $\mathrm{PCV}$ was low $(<10.0 \%)$. High GCV $(>20 \%)$ was observed for bean yield $(28.7 \%)$ and for CLR (54.8\%). Moderate GCV (10-20\%) was recorded only for
NSB (10.2\%). Low GCV $(<10.0 \%)$ was observed for the remaining 20 traits. Thus, similar to the results at Haru there was limited genetic variability for many traits in the Wollega coffee accessions included in this study. In agreement with this, Seyoum et al. [1], Yigzaw [30] and Gizachew et al. [29] found similar result using these quantitative traits (especially for leaf, fruit and bean traits) on Coffea arabica L. accessions in Ethiopia.

Broad sense Heritability at Haru and at Mugi

At Haru very high heritability $(>80 \%)$ was observed in FT, BL, BW, BT, CLR, HFPB and TNN (Table 6). Heritability for these traits was between $80 \%$ (BT) to $87 \%$ for HFPB. The current result confirmed with the finding of Wagner et al. [31] who reported the similar result using these traits.

High broad sense heritability $(\mathrm{Hb})(50-80 \%)$ was observed in NBPB, ALPB, NNPB, LW, FL, FW, PH, DM, CD, NPB, NSB and it ranged between $58 \%$ for LW to $78 \%$ for NPB. Bean yield (10\%) and LL (25\%) had low and PBPB (39\%), LA $(39 \%)$ and IL $(38 \%)$ had moderate heritability at Haru. Direct improvement of bean yield is very difficult due to its limited genetic variability and its very low heritability. Thus, indirect selection through traits that are strongly correlated with it and with higher heritability may be a better strategy for improving bean yield at Haru and at locations with similar climatic and edaphic conditions. In line with this, Dawit et al. [32] obtained experimental results that describe the positive correlation between yield and growth traits such as NBPB, ALPB, PH, NNPB, NPB and CD; these indices that the indirect selection of these yield related traits will result coffee yield improvement.

At Mugi heritability was very high ( $>80 \%)$ for BL $(89 \%)$ and BT $(84 \%)$ (Table 7$)$. It was intermediate $(50-80 \%)$ for YLD, NBPB, LA, FL, FT, PH, BW, HFPB, TNN, IL and NPB with range of $50 \%$ (LA) to $67 \%$ (IL). Moderate heritability (20-50\%) was observed in ALPB, NNPB, LL, LW, FW, CLR, DM, CD and NSB and it ranged between $31 \%$ (CLR) to $49 \%$ (CD). Although average heritability was lower at Mugi than at Haru, it was more uniform for the 23 
traits; $54+12.5$ vs $66.0+21.2$, respectively. Bean yield had higher heritability at Mugi than at Haru (55\% vs $10 \%)$ and the scope of its direct improvement through selection is better at Mugi than at Haru although its indirect improvement through index selection using other correlated traits with higher heritability is better achieved at Haru. This result conformed to the previous result described by Olika et al. [11], Lemi and Ashenafi [33] and Getachew et al. [34]. Generally, at both locations the low value of $\mathrm{Hb}$ indicated that greater value of phenotype variance than genotype variance indicating more influence of environmental factor on those traits. In contrast, high value of $\mathrm{Hb}$ showed relatively great influence of genetic factor on those traits indicating the selection of traits for the next breeding program and the possibility of improving genotypes for desired traits [31].

Genetic advance at Haru and at Mugi

Beside the estimated values of $\mathrm{GCV}$ and $\mathrm{Hb}$ in the selection process, breeders considered the magnitude of genetic advance (GA) above the population means (GAM) for selection [35]. Hence, from the present study, high GAM $(>20 \%)$ at Haru was observed in NBPB (20.2\%), CLR (101\%), HFPB (27.5\%) and NSB (32.4\%) (Table 6). Moderate GAM (10-20\%) was recorded on NNPB, FT, PH, BT, TNN, DM and NPB which range from $10.3 \%$ for NNPB to $18.2 \%$ for NPB. Furthermore, for the remaining 12 traits including bean yield (5.1\%) GAM was low $(<10 \%)$ and ranged between $4.8 \%$ for IL to $9.2 \%$ for ALFPB. This also shows that direct improvement of bean yield through selection is difficult at Haru. GAM higher than $20 \%$ was recorded on bean yield (44.0\%) and CLR (62.8\%) at Mugi (Table 7). Moderate GAM (10-20\%) was recorded for NBPB, PBPB, PH, BT, HFPB, TNN, IL, NPB and NSB with range of $10.6 \%(\mathrm{TNN})$ and $15.5 \%(\mathrm{BT})$. The remaining 12 traits had low GAM which was between $3.3 \%$ for LL and $9.8 \%$ for DM.

Table 6. Estimates of variance, coefficients of variations, broad sense heritability and genetic advance of 23 coffee traits at Haru.

\begin{tabular}{|c|c|c|c|c|c|c|c|c|c|c|c|c|}
\hline CHAR & MIN & MAX & MEAN & RNGE & GENV & EV & PHV & PCV & GCV & $\mathbf{H}$ & GA & GAM \\
\hline YLD & 172.36 & 506.89 & 345.91 & 96.71 & 752.27 & 7039.34 & 7791.62 & 25.52 & 7.93 & 0.10 & 17.56 & 5.08 \\
\hline NBPB & 9.89 & 18.11 & 13.70 & 60.03 & 2.83 & 1.63 & 4.46 & 15.42 & 12.29 & 0.64 & 2.76 & 20.19 \\
\hline РBPB & 32.59 & 49.46 & 42.47 & 39.72 & 6.10 & 9.73 & 15.84 & 9.37 & 5.82 & 0.39 & 3.16 & 7.44 \\
\hline ALPB & 71.11 & 94.67 & 82.46 & 28.57 & 18.34 & 6.30 & 24.64 & 6.02 & 5.19 & 0.74 & 7.61 & 9.23 \\
\hline NNPB & 14.92 & 19.92 & 18.02 & 27.75 & 1.07 & 0.33 & 1.41 & 6.58 & 5.75 & 0.76 & 1.86 & 10.34 \\
\hline LL & 14.82 & 16.73 & 15.71 & 12.19 & 0.05 & 0.15 & 0.20 & 2.86 & 1.42 & 0.25 & 0.23 & 1.45 \\
\hline LW & 5.71 & 7.01 & 6.33 & 20.47 & 0.05 & 0.04 & 0.09 & 4.75 & 3.61 & 0.58 & 0.36 & 5.65 \\
\hline FL & 11.54 & 15.33 & 13.62 & 27.81 & 0.34 & 0.13 & 0.48 & 5.06 & 4.30 & 0.72 & 1.02 & 7.52 \\
\hline FW & 9.19 & 11.34 & 9.90 & 21.64 & 0.15 & 0.06 & 0.21 & 4.63 & 3.94 & 0.72 & 0.68 & 6.92 \\
\hline FT & 8.50 & 10.58 & 9.09 & 22.93 & 0.25 & 0.04 & 0.29 & 5.92 & 5.46 & 0.85 & 0.94 & 10.37 \\
\hline PH & 121.44 & 170.33 & 152.26 & 32.11 & 135.63 & 46.55 & 182.18 & 8.87 & 7.65 & 0.74 & 20.70 & 13.60 \\
\hline BL & 7.18 & 8.27 & 7.63 & 14.20 & 0.09 & 0.02 & 0.11 & 4.26 & 3.86 & 0.82 & 0.55 & 7.22 \\
\hline BW & 4.44 & 5.22 & 4.76 & 16.35 & 0.05 & 0.01 & 0.05 & 4.80 & 4.50 & 0.88 & 0.41 & 8.69 \\
\hline BT & 1.83 & 2.27 & 2.03 & 21.73 & 0.01 & 0.00 & 0.02 & 6.57 & 5.88 & 0.80 & 0.22 & 10.83 \\
\hline $\mathrm{TNN}$ & 17.44 & 25.44 & 22.71 & 35.23 & 3.00 & 0.56 & 3.56 & 8.31 & 7.63 & 0.84 & 3.28 & 14.44 \\
\hline DM & 25.67 & 37.31 & 32.06 & 36.29 & 5.27 & 2.34 & 7.61 & 8.61 & 7.16 & 0.69 & 3.93 & 12.27 \\
\hline IL & 5.24 & 6.86 & 5.93 & 27.38 & 0.05 & 0.08 & 0.13 & 6.16 & 3.81 & 0.38 & 0.29 & 4.84 \\
\hline $\mathrm{CD}$ & 137.33 & 183.67 & 159.38 & 29.07 & 64.11 & 36.18 & 100.29 & 6.28 & 5.02 & 0.64 & 13.19 & 8.27 \\
\hline NPB & 25.22 & 39.67 & 32.15 & 44.93 & 10.36 & 2.89 & 13.25 & 11.32 & 10.01 & 0.78 & 5.86 & 18.23 \\
\hline NSB & 26.11 & 57.78 & 34.97 & 90.56 & 42.33 & 16.93 & 59.26 & 22.02 & 18.61 & 0.71 & 11.33 & 32.40 \\
\hline
\end{tabular}

RNG-Range, GENV-Genotype variance, EV-Environment variance, PHV-Phenotype variance, GCV\%-Genotype coefficient of variance, PCV\%-Phenotype coefficient of variance, H-Broad sense heritability, GA-Genetic advance, GAM\%-Genetic mean advance, PH-Plant height (cm), HFPB-Height up to the first primary branch (cm), TNN-Total node number of main stem, DM-Diameter of main stem (mm), IL-Internodes' length of main stem (cm), CD-Canopy diameter $(\mathrm{cm})$, NPB-Number of primary branch, NSB-Number of Secondary branch, NBPB-Number of bearing primary branch, PBPB-Percent of bearing primary branch, ALPB-Average length of primary branch $(\mathrm{cm})$, NNPB-Number of nodes per primary branch, LL-Leaf length (cm), LW-Leaf width (cm), LALeaf area $\left(\mathrm{cm}^{2}\right)$, FL-Fruit length $(\mathrm{mm})$, FW-fruit width $(\mathrm{mm})$, FT-Fruit thickness $(\mathrm{mm})$, BL-Bean length (mm), BW-Bean width (mm), BT-Bean thickness (mm), YLD-Yield (kg/ha, and CLR-Coffee leaf rust (\%).

Table 7. Estimates of variance, coefficients of variations, broad sense heritability and genetic advance of 23 coffee traits at Mugi.

\begin{tabular}{llllll}
\hline CHAR & MIN & MAX & MEAN & RNG (\%) & GENV \\
\hline YLD & 257.15 & 1235.94 & 486.08 & 201.36 & EV \\
NBPB & 15.56 & 24.15 & 20.57 & 41.80 & 19467.11 \\
PBPB & 41.15 & 64.10 & 52.79 & 43.47 & 3.15 \\
ALPB & 81.69 & 111.12 & 88.94 & 33.08 & 23.59 \\
NNPPB & 17.58 & 23.39 & 19.49 & 29.82 & 18.24 \\
LL & 14.39 & 16.96 & 15.24 & 16.87 & 0.96 \\
LW & 6.00 & 7.10 & 6.36 & 17.38 & 0.13 \\
LA & 59.09 & 73.85 & 64.99 & 22.70 & 0.03 \\
FL & 12.69 & 15.65 & 13.67 & 21.63 & 0.15 \\
\hline
\end{tabular}




\begin{tabular}{lllllll}
\hline CHAR & MIN & MAX & MEAN & RNG (\%) & GENV & EV \\
\hline FW & 10.41 & 11.88 & 11.01 & 13.36 & 0.06 & 0.06 \\
FT & 8.03 & 9.68 & 9.26 & 17.76 & 0.05 & 0.04 \\
PH & 179.89 & 251.86 & 204.34 & 35.22 & 237.47 & 171.29 \\
BL & 6.70 & 8.25 & 7.37 & 21.10 & 0.14 & 0.02 \\
BW & 4.43 & 5.04 & 4.71 & 13.04 & 0.01 & 0.01 \\
BT & 1.93 & 2.72 & 2.23 & 35.05 & 0.03 & 0.01 \\
CLR & 5.50 & 36.64 & 14.21 & 219.14 & 17.41 & 34.88 \\
HFPB & 21.33 & 35.09 & 27.97 & 49.20 & 5.51 & 4.73 \\
TNN & 25.00 & 37.59 & 28.61 & 44.01 & 3.80 & 2.84 \\
DM & 35.17 & 52.84 & 40.62 & 43.50 & 7.86 & 8.68 \\
IL & 5.42 & 7.99 & 6.41 & 40.08 & 0.29 & 0.14 \\
CD & 167.94 & 220.04 & 183.47 & 28.39 & 104.23 & 106.59 \\
NPB & 33.67 & 50.82 & 39.39 & 43.55 & 9.23 & 7.22 \\
NSB & 35.00 & 72.22 & 49.08 & 75.84 & 26.76 & 33.30 \\
\hline
\end{tabular}

Table 7. Continued.

\begin{tabular}{|c|c|c|c|c|c|c|}
\hline CHAR & PHV & PCV & GCV & $\mathbf{H}$ & GA & GAM \\
\hline YLD & 35153.86 & 38.57 & 28.70 & 0.55 & 213.89 & 44.00 \\
\hline NBPB & 5.47 & 11.37 & 8.63 & 0.58 & 2.77 & 13.48 \\
\hline РBPB & 43.04 & 12.43 & 9.20 & 0.55 & 7.41 & 14.03 \\
\hline ALPB & 41.70 & 7.26 & 4.80 & 0.44 & 5.82 & 6.54 \\
\hline NNPPB & 2.11 & 7.45 & 5.02 & 0.45 & 1.36 & 6.97 \\
\hline LL & 0.27 & 3.44 & 2.36 & 0.47 & 0.51 & 3.33 \\
\hline LW & 0.06 & 3.97 & 2.60 & 0.43 & 0.22 & 3.52 \\
\hline FL & 0.45 & 4.90 & 3.58 & 0.53 & 0.74 & 5.39 \\
\hline FW & 0.12 & 3.15 & 2.20 & 0.49 & 0.35 & 3.17 \\
\hline FT & 0.10 & 3.37 & 2.53 & 0.56 & 0.36 & 3.92 \\
\hline PH & 408.76 & 9.89 & 7.54 & 0.58 & 24.20 & 11.84 \\
\hline $\mathrm{BL}$ & 0.16 & 5.38 & 5.09 & 0.89 & 0.73 & 9.91 \\
\hline BW & 0.02 & 3.18 & 2.40 & 0.57 & 0.18 & 3.74 \\
\hline BT & 0.04 & 8.99 & 8.22 & 0.84 & 0.35 & 15.48 \\
\hline HFPB & 10.24 & 11.44 & 8.40 & 0.54 & 3.55 & 12.69 \\
\hline $\mathrm{TNN}$ & 6.64 & 9.01 & 6.82 & 0.57 & 3.04 & 10.63 \\
\hline $\mathrm{DM}$ & 16.54 & 10.01 & 6.90 & 0.48 & 3.98 & 9.80 \\
\hline IL & 0.43 & 10.22 & 8.34 & 0.67 & 0.90 & 14.04 \\
\hline $\mathrm{CD}$ & 210.82 & 7.91 & 5.56 & 0.49 & 14.79 & 8.06 \\
\hline NPB & 16.44 & 10.29 & 7.71 & 0.56 & 4.69 & 11.90 \\
\hline NSB & 60.06 & 15.79 & 10.54 & 0.45 & 7.11 & 14.49 \\
\hline
\end{tabular}

RNG-Range, GENV-Genotype variance, EV-Environment variance, PHV-Phenotype variance, GCV\%-Genotype coefficient of variance, PCV\%-Phenotype coefficient of variance, H-Broad sense heritability, GA-Genetic advance, GAM\%-Genetic mean advance, PH-Plant height (cm), HFPB-Height up to the first primary branch (cm), TNN-Total node number of main stem, DM-Diameter of main stem (mm), IL-Internodes' length of main stem (cm), CD-Canopy diameter (cm), NPB-Number of primary branch, NSB-Number of Secondary branch, NBPB-Number of bearing primary branch, PBPB-Percent of bearing primary branch, ALPB-Average length of primary branch $(\mathrm{cm})$, NNPB-Number of nodes per primary branch, LL-Leaf length $(\mathrm{cm})$, LW-Leaf width (cm), LALeaf area $\left(\mathrm{cm}^{2}\right)$, FL-Fruit length $(\mathrm{mm})$, FW-fruit width $(\mathrm{mm})$, FT-Fruit thickness $(\mathrm{mm})$, BL-Bean length (mm), BW-Bean width (mm), BT-Bean thickness $(\mathrm{mm})$, YLD-Yield (kg/ha, and CLR-Coffee leaf rust (\%)

Genetic advance, $\mathrm{Hb}$ and $\mathrm{GCV}$ all together provide information of successfully to improve traits of genotypes. When high, Hb, GCV and GAM value combined for desired traits, the involvement of additive gene action expected in that traits. Therefore, at Haru moderate genotypic variance, high heritability and high GAM were observed for NBPB, HFPB and NSB. These traits can be used as indices for improving bean yield which had low heritability and low GAM at Haru. At Mugi bean yield and CLR had high genotypic variance and high genetic advance as percent of the mean although CLR had moderate heritability. Hence, bean yield and CLR can be easily improved via selection at Mugi and at other coffee growing areas with similar soil and climatic conditions. From the population of the top 5\% most performing genotypes it is possible to improve yield by $213.89 \mathrm{~kg} \mathrm{ha}^{-1}$ at Mugi and CLR by $5.37 \%$ at Mugi and $2.46 \%$ at Haru per cycle of selection. Leaf traits (LL, LW, LA), Fruit traits (FL, FW, FT), bean traits (BL, BW), and ALFPB had low GCV and low GAM at both locations. The improvement of these traits seems to be difficult. High $\mathrm{Hb}$ with low GAM recorded for many traits expressing traits governed by non-additive gene action. For these traits improvement via cross (hybridization) is better than direct selection. In agreement with the present result, Olika et al. [11], Masreshaw [27] and Gizachew et al. [29] reported similar result for yield and yield related traits used under this study.

\section{Conclusion}

The current study at both locations indicated the existence of significant difference among tested coffee 
genotypes in most traits indicating availability of moderate genetic variability between tested genotypes. The combined analysis of variance of quantitative traits showed significant difference among coffee genotypes only in few numbers of traits although 18 and 22 of the 23 traits showed significant difference among genotypes at Haru and at Mugi, respectively. This was caused by the significant $\mathrm{GxE}$ interaction against which genotypes mean square were tested. GxE interaction was significant for all traits except number of nodes per primary branch (NNPB), leaf length (LL), fruit width (FW) and Coffee leaf rust (CLR) indicating non stability performance of coffee genotypes across locations. This indicated that the identification of genotypes with high performance over a wide coffee producing area is very difficult. Hence, it is better to divide coffee growing areas into similar ecologies, some similar to Haru and others similar to Mugi and focus on developing coffee varieties with specific adaptation to these ecologies.

At Haru, moderate genotypic variance, high heritability and high genetic advance as percent of the mean (GAM) were observed for number of bearing primary branch, height up to the first primary branch and number of secondary branch. These traits can be used as indices for improving bean yield which had low heritability and low GAM. At Mugi, bean yield and CLR had high genotypic variance and high GAM; in such condition additive gene action may expect. Hence, Bean yield and CLR can be easily improved via selection at Mugi and at other coffee growing areas with similar soil and climatic conditions.

\section{Acknowledgements}

We would like to thank Ethiopian Institute of Agricultural Research for financial support of the study and Mugi and Haru Agricultural research sub center staff for their support during data collection.

\section{References}

[1] Seyoum S, Singh H, Bellachew B (2004) Diversity in the Ethiopia Coffee (Coffea arabica L.) Germplasm. In ASIC 20th Colloquium, India, Bangalore.

[2] Wintgens JN (2009) Coffee: growing, processing, sustainable production. A guidebook for growers, processors, traders and researchers. Wiley-Vch, Verlag, 976p.

[3] Couturon E, Raharimalala NE, Rakotomalala JJ, Hamon S, de Kochko A, Guyot R, Hamon P (2016) Wild coffee-trees: a threatened treasure in the heart of tropical forests. Caféiers Sauvages: Un Trésor en Péril au Cour des Forêts Tropicales (Private publication, 2016).

[4] Herbert V, Beno1^t B, Andre'Ch (2015) Next generation variety development for sustainable production of arabica coffee (Coffea arabica L.): a review. Euphytica. DOI: 10.1007/s10681-015-1398-z.

[5] Ky C-L, Louarn J, Dussert S, Guyot B, Hamon S, Noirot M
(2001) Caffeine, trigonelline, chlorogenic acids and sucrose diversity in wild Coffea arabica L. and C. canephora P. accessions. Food chem. 75: 223-230.

[6] Leroy T, Ribeyre F, Bertrand B, Charmetant P, Dufour M, Montagnon C, Marraccini P, Pot D (2006) Genetics of coffee quality. Braz. J. Plant Physiology 18: 229-242.

[7] Fernie L M (1966) Some Impressions of Coffee in Ethiopia. Kenya Coffee 31: 115-121.

[8] Labouisse JP, Bellachew B (2008) Current status of Coffee (Coffea arabica L.) genetic resources in Ethiopia: implications for conservation. Genetic Res. and Crop Evol. 55: 1079.

[9] Mesfin K, Bellachew B (2008) Phenotypic diversity in the harage Coffee (Coffea arabica L.) germplasm for quantitative traits. East Afr. J. Sci. 2: 13-18.

[10] Abdulfeta T K (2018) Characterization and Yield Performance Evaluation of Coffee (Coffea arabica L.) Germplasm Accessions from Tepi, Southwestern Ethiopia MSc. Thesis summated to Hawassa University College of Agriculture. 71p.

[11] Olika K, Alamerew S, Kufa T, Garedew W (2011) Genetic Diversity Analysis of Limmu Coffee (Coffea arabica L.) Collection using Quantitative Traits in Ethiopia. Int. J. Agric. Res. 6: 470-481.

[12] Moat J, William J, Beana S, Wilkinson T, Gole TW, Chala ZK, Demmissew S, Davis AP (2017) Resilience potential of the Ethiopian coffee sector under climate change. Nat. Plants 3: 17081.

[13] CTA (1999) Uniqueness of Ethiopian coffee. In: Ethiopia: the cradle of the wonder bean Coffea arabica L. (abissinica). Coffee and Tea Authority (CTA), Addis ababa. pp. $28-30$.

[14] Mesfin A, Bellachew B (1987) Genotype x environment interaction in Coffee (Coffea arabica L.), 29 June - 3 July, 1987. In: Fourth international colloquium on coffee (ASIC 87). pp. $476-482$.

[15] Dubale P (2001) Soil and Water Resources and Degradation Factors Affecting their Productivity in the Ethiopian Highland Agro ecosystems. Int. Conf. on African Dev. Archives. Pp 1-21.

[16] Alemseged Y, Kuffa T (2002) Characterization of the farming Systems of Haru Woreda. West Wollega zone, Oromia region. Research Report (44) EARO. pp. 38.

[17] IAR (1996) Recommended Production Technologies for Coffee and Associated Crops. Institute of Agricultural Research, Addis Ababa. 18p.

[18] IPGRI (1996) Descriptors for Coffea sp. \& Psilanthus sp, International Plant Genetic Resource Institute, Rome. 35p.

[19] SAS (Statistical Analysis System) software (2004) Version 9.0, SAS Institute, Cary, NC, USA.

[20] Hartley H O (1950) The maximum F-ratio as a short cut test for heterogeneity of variances. Biometrika 37: 308-312.

[21] Johnson H W, Robinson H F, Comstock RF (1955) Genotypic and phenotypic correlation in Soya bean and their implication in selection. Agro. Jour. 47: 477-483.

[22] Deshmukh S N, Basu MS, Reddy PS (1986) Genetic variability, character association and path coefficient analysis of quantitative traits in Virginia bunch varieties of groundnut. Indian J. Agric. Sci. 56: 816-821. 
[23] Allard RW (1960) Fundamentals of Plant Genetics and Breeding. John Willey \& Sons, New York. England.

[24] Holland J B, Nyquist WE, Cervantes Martinez CT (2003) Estimating and Interpreting Heritability for Plant Breeding. In J. Janick (Ed.) Plant Breeding Reviews. Wiley, New York. pp. 9-111.

[25] Robinson H F, Comstock RE, Harvey PH (1949) Estimates of heritability and degree of dominance in corn. Agro. Jour. 41: $353-359$.

[26] Mota JM, Barros RS, DaMatta FM (1997) Vegetative growth in Coffea arabica L. as affected by irrigation, day length and fruiting. Trop. Ecol. 38: 73-79.

[27] MasreshawY H (2018) Genetic Variability in Yayu Coffee (Coffea arabica L.) Germplasm at Metu, Southwestern Ethiopia MSc. Thesis summated to Jimma University College of Agriculture and Veterinary Medicine. 80p.

[28] Fekadu T, Sentayehu A, Dange W (2016) Assessment of the Growth and Yield Characters of Some Promising Arabica coffee Hybrids under Highland Environments in Southwestern Ethiopia. American-Eurasian J. Agric. \& Environ. Sci. 16: 917-923.

[29] Gizachew A, Mohammed H, Kufa T (2017) Genetic Variability of Sidama Coffee (Coffea arabica L.) Landrace for Agro-morphological Traits at Awada, Southern Ethiopia. Acad. Res. J. Agri. Sci. Res. 5: 263-275.
[30] Yigzaw D (2005) Assessment of cup quality, morphological, biochemical and molecular diversity of Coffea arabica L. genotypes of Ethiopia. PhD. Thesis, University of Free State, Suoth Afirica. 215p.

[31] Wagner N R, Marcelo AT, José FT, Maria A G, Tafarel V C, Márcio A A, Leonardo F C (2014) Biometrical studies on characteristics of plagiotropic branches in Coffea arabica L. cultivated with high plant density. Australian J. of Crop Sci. 8: 1239.

[32] Dawit M, Hussein M, Ashenafi A (2019) Correlation and Path Coefficient Analysis of Quantitative Traits in Some Wollega Coffee (Coffea arabica L.) Landrace in Western Ethiopia. J. of Env. and Earth Sci. 9: 2224-3216.

[33] Lemi B, Ayano A (2016) Genetic Variability, Heritability and Genetic Advance for Yield and Yield Components of Limmu Coffee (Coffea arabica L.) Accessions in South Western Ethiopia. Middle-East J. Sci. Res. 24: 1913-1919.

[34] Getachew W, Alamerew S, Kufa T (2017) Genetic variability, heritability and genetic advance for quantitative traits in Coffee (Coffea arabica L.) accessions in Ethiopia. African J. Agric. Res. 12: 1824-1831.

[35] Rubiyo R, Edi W (2013) Analysis of genetic parameters for bean physical quality characters and clusterizations of eleven genotypes of robusta coffee (Coffea canephora P.). Indonesian J. Agric. Sci. 14: 55-62. 